\title{
Determination of Antimüllerian Hormone Levels and its Relationship with the Number of Follicles and Ovary Size in Heifers and Adult Brahman Females
}

\author{
Macías-Andrade $\mathrm{JI}^{1,2, *}$, Hurtado $\mathrm{EA}^{1}$, Carreño-Mendoza $\mathrm{AL}^{1}$, and Vivanco-Mackie $\mathrm{HW}^{2}$ \\ ${ }^{1}$ Polytechnic Agricultural College of Manabí, Manabí, Ecuador \\ ${ }^{2}$ National Agrarian University, Lima, Perú
}

*Corresponding author: Macías-Andrade JI, Polytechnic Agricultural College of Manabí, Manabí, Ecuador, E-mail: jorgeignaciomacias@hotmail.com

Received: 08 Jan, 2020 | Accepted: 04 Feb, 2020 | Published: 11 Feb, 2020

Citation: Macías-Andrade JI, Hurtado EA, Carreño-Mendoza AL, Vivanco-Mackie HW (2020) Determination of Antimüllerian Hormone Levels and its Relationship with the Number of Follicles and Ovary Size in Heifers and Adult Brahman Females. J Anim Sci Res 4(1): dx.doi.org/10.16966/25766457.133

Copyright: (C) 2020 Macías-Andrade Jl, et al. This is an open-access article distributed under the terms of the Creative Commons Attribution License, which permits unrestricted use, distribution, and reproduction in any medium, provided the original author and source are credited.

\section{Summary}

The study was carried out in the central coast region of Ecuador, municipality of Paján, province of Manabí. The objective was to determine the functional relationship between the levels of Antimüllerian Hormone (AMH), follicle count, age of the individual and ovary size of Brahman females. Sixty $(60)$ bovine females aged between 18 and 132 months were randomly selected from a high genetic value Brahman cattle population and were subjected to gynecological examination using ultrasonography to verify ovarian activity. In addition, an ovulation synchronisation protocol was performed on all the females. Blood samples were taken for determination of serum AMH levels by an ELISA test using MOFA ${ }^{\oplus}$ kits for the analysis of samples. Follicle count and size of the ovary were evaluated through endorectal ultrasonography. The data and the relationship between the variables under study were examined through regression analysis. Plasma levels of AMH decreased with age of the individual; an inverse linear adjustment was obtained between AMH levels and age and among small follicles, total follicles and age, showing signs of depletion of the ovarian reserve over time. We observed a direct linear relationship between ovary size and follicle count.

Keywords: Antimüllerian hormone; Follicles; Ovarian size; Brahaman cattle; Age influence

\section{Introduction}

Reproductive efficiency is a determining factor of the economic performance that bovine herds yield. The reproductive life of bovine females is established since the beginning of fetal development, in which the preparation of the reproductive system in cattle begins [1]. At the time of birth, the ovaries already have the potential for the production of oocytes contained in a fixed number of primordial follicles, which are known as the ovarian reserve and constitute the structures that trigger the reproductive processes and phases of the estrous cycle (Ireland JJ, et al. [2], Findlay JK, et al. [3]). The number of follicles and oocytes is very variable throughout the reproductive life of adult mammals. This is due to, as documented, that mammals are born with a very variable number of morphologically healthy follicles and oocytes, this amount begins to decrease rapidly with aging and they never get replenished. Erickson BH, et al. [1] reported that at the age of 1 year, cows have lost $80 \%$ of their original stock of healthy oocytes.

Antral follicle count has been related to reproductive parameters such as ovary size, corpus luteum diameter, number of healthy oocytes, endometrial thickness, progesterone concentration, pregnancy rate, and other reproductive indices (Singh J, et al. [4], Cushman RA, et al. [5]; Modina SC, et al. [6]; Jimenez-Krassel F, et al. [7]; Martinez MF, et al. [8]). Based on this antral follicle count relationship with other reproductive parameters related with fertility it has been proposed by Silva-Santos KC, et al. [9], and Morotti F, et al. [10], that selection of egg-donor cows could be performed using a single ultrasound examination of follicle numbers at the beginning of their reproductive life. Similarly, Antimüllerian Hormone (AMH) has been recognized as an indicator of ovarian response to super ovulation protocols (Souza AH, et al. [11]) and it is highly correlated with antral follicle count and the viability of oocytes (Baruselli PS, et al. [12]).

Monniaux D, et al. [13] proposed that the $\mathrm{AMH}$ whose expression is restricted to the granulosa cells of the ovarian follicles in development could be used as an endocrine marker of the size of the nest of antral follicles in the ovary. Gobikrushanth $\mathrm{M}$, et al. [14] pointed out that antral follicle count and circulating AMH concentrations increased in line with the increase in recruitment of ovarian follicles until cows reached five years of age and then decreased as a consequence of the gradual exhaustion of the ovarian reserve.

It is expected that age has a negative effect on antral follicle count and that the evaluation of the reproductive tract in heifers represents an effective approach to an indicator for fertility status in any herd (Cushman RA, et al. [5]). On the other hand, Zangirolamo AF, et al. [15] indicates that, the antral follicle count represents an auxiliary tool for the selection of animals that have a much greater quantitative potential of embryos. 
Several studies have attempted to determine the morphological or phenotypic characteristics that contribute to predicting the reproductive behaviour in cattle. The total count of antral follicles reflects the reserve of ovarian follicles, this has a very close relationship with the degree of fertility in cows (Danielle M, et al. [16], Martinez MF, et al. [8]). In this sense, Morotti F, et al. [17], studied the correlations between antral follicular count and fertility parameters in heifers and beef cows, finding conflicting results regarding their repetitiveness in bos indicus cattle. Maculan R, et al. [18] found associations between ovary size and antral follicle count in Bos taurus females. Similarly, a higher follicle count was obtained in Holstein cows (Ireland JLH, et al. [19]) and Angus heifers (Eborn DR, et al. [20]) that presented a larger ovary size. The main interest is focused on making decisions about the selection of replacement heifers at an early age, which would allow animals with low fertility to be quickly removed from the herd and destined for other purposes, thus enhancing the profitability of the production system.

Despite many studies on follicular dynamics and its relationship with fertility and efficiency of reproductive biotechnologies, the conditioning factors and mechanisms involved in the process are not yet completely understood and there is no information on these relationships in Bos indicus. Therefore, the objective of this study was to evaluate the functional relationship among plasma levels of $\mathrm{AMH}$, follicle count, age and ovary size in Brahman females.

\section{Materials and Methods}

\section{Location}

The study was carried out in the Brahaman cattle herd of the Aura Germania Company, located in the municipality of Paján, province of Manabí, Ecuador, at $01^{\circ} 33^{\prime} 0^{\prime \prime} \mathrm{S}, 80^{\circ} 25^{\prime \prime} 60^{\prime \prime} \mathrm{W}$ and an altitude of $110 \mathrm{mosl}$, with an average annual temperature of $24^{\circ} \mathrm{C}$ and an average annual rainfall of $1500 \mathrm{~mm}$. The AMH analyses were conducted in the Biotechnological Laboratory of the Polytechnic Agricultural College of Manabí, Ecuador.

The herd is made up of 1,500 head of Brahaman cattle of different ages and physiological stages, kept in paddocks, fed mainly on Cynodon nlemfuensis and Panicum maximum (Saboya) grass and supplemented with concentrated minerals to meet nutritional requirements according to age, weight, and physiological stage. Water was supplied from natural sources.

\section{Research subjects and trial management}

Sixty (60) bovine females aged between 18 and 132 months were selected from a population of high genetic value cattle of the Brahman breed which were subjected to gynecological examination using ultrasonography to evaluate ovarian activity. An ovulation synchronization protocol was carried out to equalize the start of the estrous cycle in all the animals, for this, a device with progesterone was inserted on Day 0 (DIB 0.5 Zoetis) and a dose of $2 \mathrm{mg}$ estradiol benzoate (Gonadiol $1 \mathrm{mg} / \mathrm{mL}$; Zoetis benzoate), on Day 8 the device was removed, Injected $0.15 \mathrm{mg}$ of prostaglandin (Ciclase, Zoetis), 1 $\mathrm{mg}$ of estradiol benzoate was injected on day 9. All blood samples for AMH determination were taken on the day the synchronization protocol was initiated, before hormonal application.

\section{Variables and methods}

A $4 \mathrm{ml}$ of blood was extracted by means of a puncture in the jugular vein, using BD Vacutainer ${ }^{\circledast} \mathrm{NH}$ tubes (Becton Dickinson and Co.) under vacuum with sodium heparin. This blood was then subjected to refrigerated centrifugation at $3,200 \mathrm{gr}$ for 10 minutes at $4^{\circ} \mathrm{C}$ and subsequently stored immediately at $-20^{\circ} \mathrm{C}$ until ELISA.
Serum samples were thawed in a water bath just before the ELISA; they were shaken in a "vortex" and centrifuged at 3,200 gr for 10 minutes at $4^{\circ} \mathrm{C}$. Then, they were incubated for 12 hours at $4^{\circ} \mathrm{C}$ in the presence of a first antibody; and after this, 1.5 hours more at room temperature in the presence of the second antibody to finally see the readings.

The determination of the serum AMH levels were made by ELISA test, MOFA "KITS" (AMH ELISA simple test Kit Bovine Serum, 40 samples Max/Kit 21700/100) and the readings were taken with the "Infinite 200 PRO Multimode Multiplate Reader" following the methods described by Monniaux D, et al. [21]; Rico C, et al. [22]. The concentrations of $\mathrm{AMH}$ were quantified using $50 \mu \mathrm{L}$ serum samples.

The number and size of the follicles were determined with ultrasound (Mindray DP $50 \mathrm{VET}^{\oplus}$, Shenzhen, China) and $7.5 \mathrm{MHz}$ linear transducer in $\mathrm{B}$ mode, measuring and contacting the follicles, from the beginning of the follicular wave, the days 4, 6 and 8 of the beginning of the initiation protocol. The corpus luteum size was measured with the same equipment at 72 hours after the signs of heat, and the size of the ovary was measured in $\mathrm{cm}$, also by endorectal ultrasound at the beginning of the protocol.

All young females showed mature graff follicles, although not all had corpus luteum.

\section{Data analysis}

Several statistical measures to describe the variables were taken, measures of central tendency (means) and dispersion (standard deviation and standard error of the mean). Additionally, through regression analysis we determined the degree of functional relationship of the variables. We adjusted the relationships between cow age and the AMH levels, age and number of follicles (small 2-4mm, large $>4$ $\mathrm{mm}$, and total) and similarly, ovary size in relation to follicle size (small, large and total). The statistical analyzes were performed with the InfoStat ${ }^{\oplus}$ software.

\section{Results}

The descriptive analysis of the variables is shown in table 1 . It can be observed that the average AMH level was $297.25 \mathrm{\rho g} / \mathrm{ml}$, while the median was $250.65 \mathrm{\rho g} / \mathrm{ml}$, reflecting an average value closer to the third quartile $(310.4 \mathrm{gg} / \mathrm{ml})$, which results in a left-skewed distribution, with an impact on the average value, with few values pointing to the highest $\mathrm{AMH}$ levels. This situation is evidenced by the high coefficients of variation obtained from the AMH levels (62.46\%).

For the variables number of small follicles, large follicles and total follicles, the mean and the median showed similar values, which is indicative of a normal distribution of the data; the average values were $20.68 ; 14.22$ and 34.88 with coefficients of variation of $49.50,36.29$ and 39.83 for the small, large and total follicles, respectively. Similarly, the size of the corpora lutea and ovary also showed comparable mean and median values with relatively low coefficients of variation.

\section{Relationship between cattle age and follicle count}

For the relationship between cattle age and follicle count, we made a significant and inverse linear adjustment for variables small follicles and total follicles, where it is evident that as the age of the cow increases, the quantity of small and total follicles decreases (Figure 1). In the case of the number of small follicles the equation was adjusted to $\hat{y}=-0.12 x+27.3$, with a coefficient of determination of 0.55 ; while for the total number of follicles the adjustment corresponded to the 
Table 1: Descriptive summary of variables antimüllerian hormone $(\mathrm{\rho g} / \mathrm{ml})$, follicle count, size of the corpora lutea (mm) and ovary size (cm) of Bos indicus females.

\begin{tabular}{|c|c|c|c|c|c|c|c|}
\hline Variable & $\mathbf{N}$ & Mean & Median & First quartile & Third quartile & Standard deviation & Coefficient of variation \\
\hline $\mathrm{AMH}(\rho \mathrm{g} / \mathrm{ml})$ & 60 & 297.25 & 250.65 & 197.4 & 310.4 & 185.65 & 62.46 \\
\hline Small follicles & 60 & 20.68 & 18.50 & 13 & 27 & 10.24 & 49.50 \\
\hline Large follicles & 60 & 14.22 & 13.00 & 11 & 18 & 5.16 & 36.29 \\
\hline Total follicles & 60 & 34.88 & 34.00 & 24 & 42 & 13.89 & 39.83 \\
\hline Corpus luteum (mm) & 41 & 13.66 & 13.80 & 12 & 15 & 3.30 & 24.14 \\
\hline Right ovary $(\mathrm{cm})$ & 59 & 2.82 & 2.80 & 2.4 & 3.1 & 0.46 & 16.44 \\
\hline Left ovary $(\mathrm{cm})$ & 59 & 2.79 & 2.72 & 2.25 & 3.37 & 0.64 & 23.10 \\
\hline
\end{tabular}

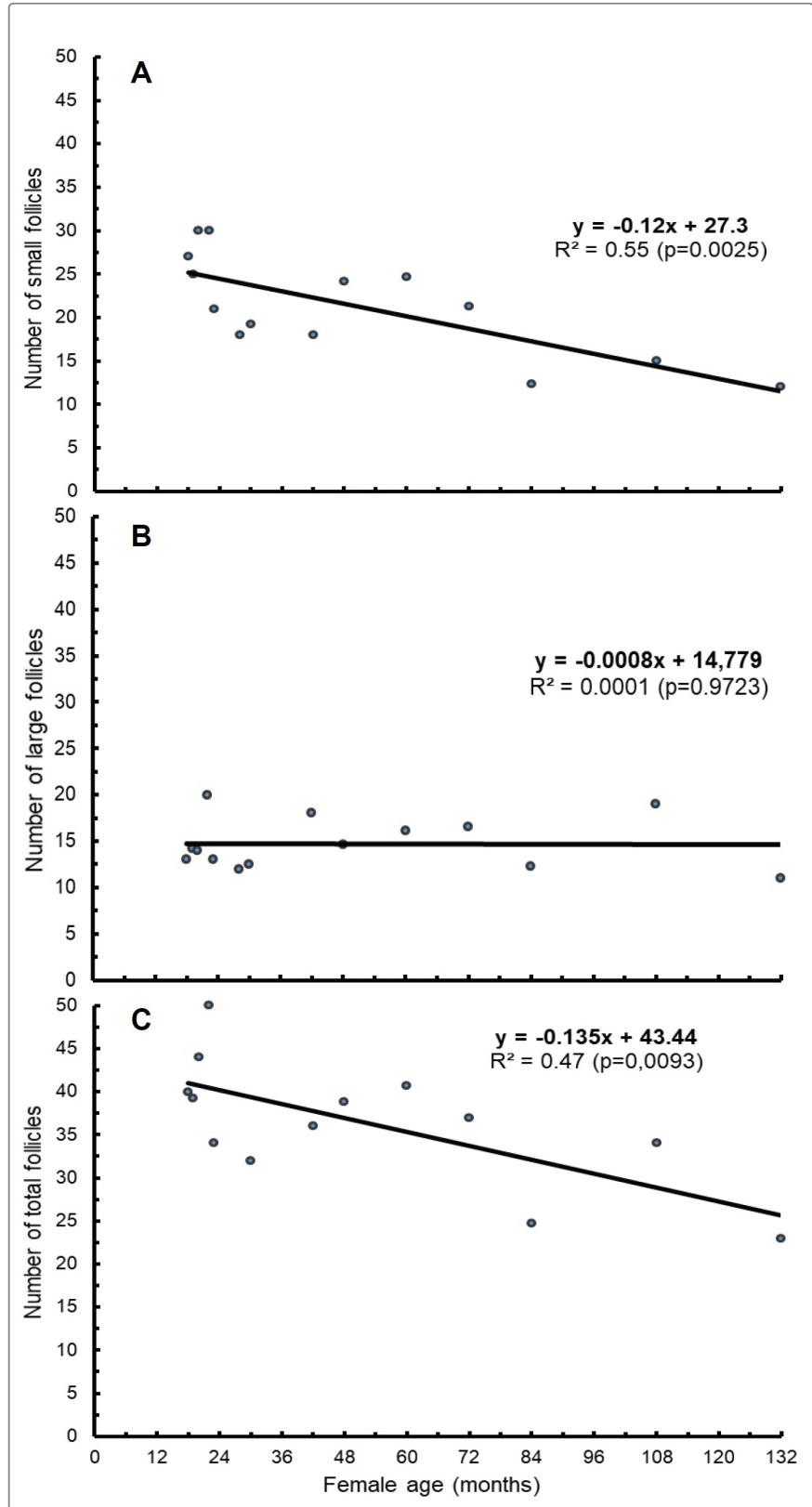

Figure 1: Correlation among Brahman female age and number of small (A), large (B) and total (C) follicles.

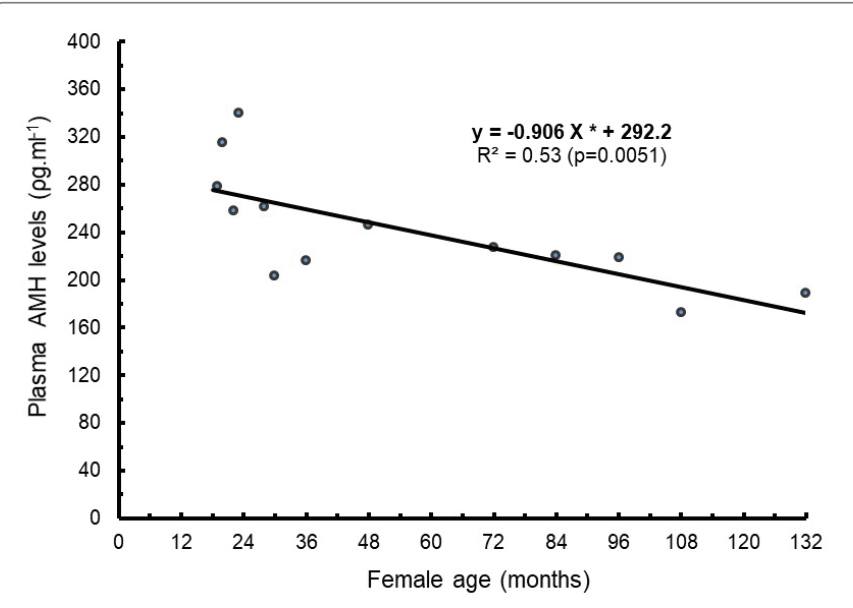

Figure 2: Relationship between the age of Brahman females and plasma levels of the antimüllerian hormone.

equation: $\hat{y}=-0.135 x+43.44$, with a coefficient of determination of 0.47. The adjustment equation for the number of large follicles was not significant.

The relationship between cattle age and levels of AMH (Figure 2) shows an inverse cause-effect association with a linear adjustment represented by the equation $\hat{y}=-0.906 \mathrm{X}+292.2$ and a coefficient of determination of 0.53 ; these findings confirm the occurrence of the highest plasma levels of AMH in animals aged between 18 and 24 months. The levels of AMH consolidate what is indicated in Figure 1concerning the follicle population, which also showed larger follicular population between 18 to 24 months and then a tendency to decrease with the age of the animal.

\section{Ovary size and follicle count}

For the case of the number of small follicles (Figure 3), the equation was adjusted to $\hat{y}=14.38 \mathrm{x}-22.45$ with a coefficient of determination of 0.42. As for the number of large follicles, the adjusted equation was $\hat{y}=6.35 x-4.18$ with a coefficient of determination of 0.20 ; while for the total number of follicles the adjustment corresponded to the equation: $\hat{y}=17.95 x-19.32$ with a coefficient of determination of 0.34 . It should be noted that although the coefficients were significant, the adjustments to the equations are relatively small and in general, they explain a very low proportion of the results through ovary size, which is complemented through the relationships described for the serum $\mathrm{AMH}$ and the age of the animal (see Figures 1 and 2). 


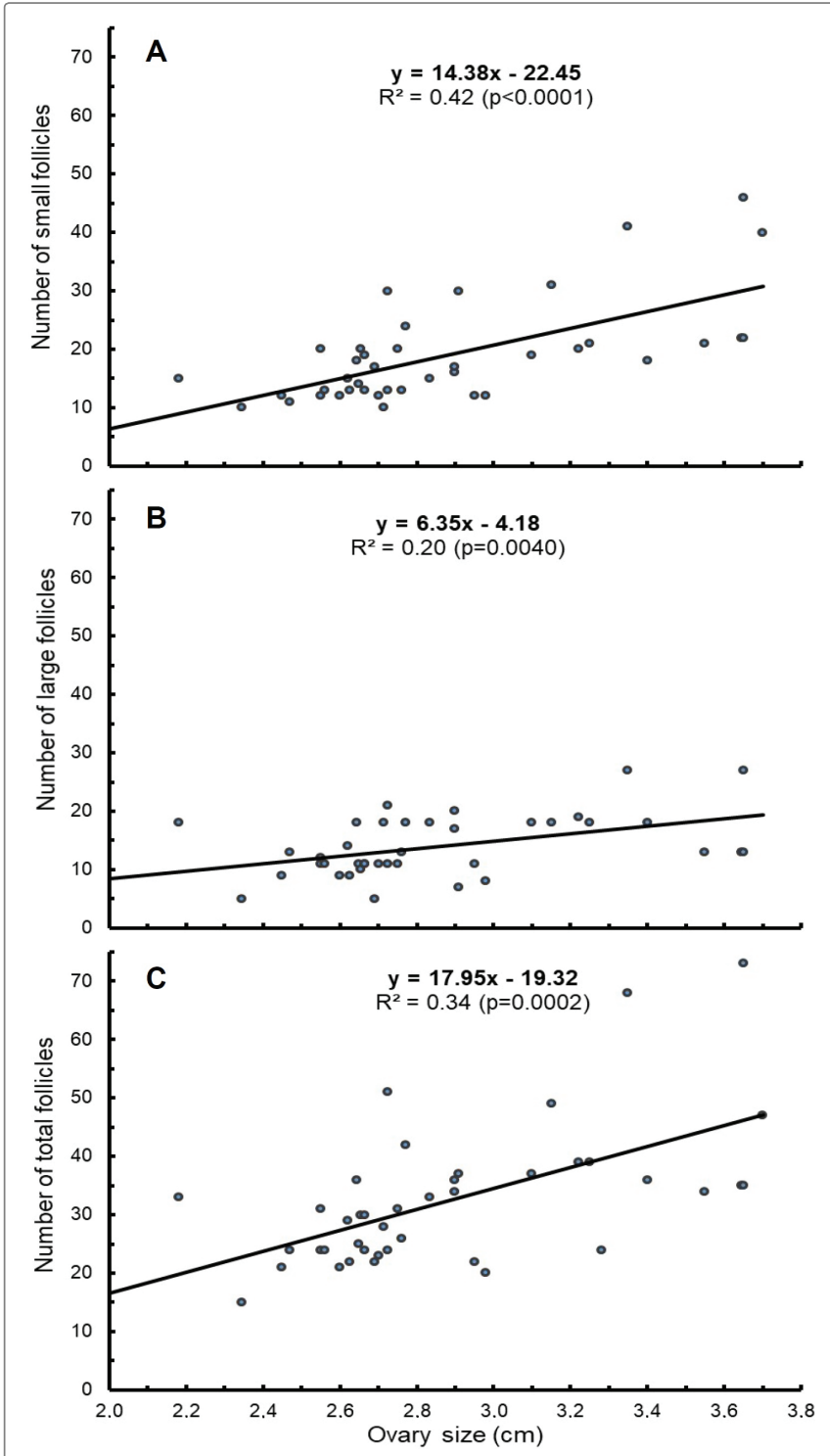

Figure 3: Relationship between ovary size of Brahman cows and heifers and number of small (A), large (B) and total (C) follicles.

\section{Discussion and Conclusion}

Our results show an inverse relationship between age and number of follicles, this is similar to what was reported by Ireland JJ, et al. [23] who found a seven-fold difference in the number of antral follicles of young versus adult cattle but observed greater consistency within individuals for the number of antral follicles within the follicular waves. This represents a very useful marker for the identification of potential Brahman embryo donor females.

The decrease in the number of follicles with age represents a rational biological behavior because the number of follicles reflects the state of the ovarian follicle reserve, therefore, it is expected that older animals have smaller follicle reserves and consequently, fewer follicles. This relationship was observed in Holstein cows (Burns DS, et al. [24]) and mestizo females (Cushman RA, et al. [5]). Koyama K, et al. [10] reported similar results for dairy cattle, also pointing out the repeatability of the number of antral follicles from the first to the third parturition and reduction from the fourth calving.
Monniaux D, et al. [21] state that ovarian reserves in cattle remain relatively constant until they reach the age of approximately 4 to 6 years and descend subsequently, similarly, Cushman RA, et al. [5] revealed a decrease in antral follicle count from the age of 5 years in beef cattle. In our study, the largest follicle population is present in the youngest animals, and a gradual decrease was observed as the age of the animals increased.

Gobikrushanth M, et al. [14] pointed out that antral follicle count and circulating AMH concentrations increased in line with the increase in recruitment of ovarian follicles until cows reached five years of age and then decreased as a consequence of the gradual exhaustion of the ovarian reserve, in figure 2 it can be observed that in our results the AMH level decreases after 72 months (3 years of age).

In contrast, Hirayama $\mathrm{H}$, et al. [25] found no links between age and $\mathrm{AMH}$ concentrations or antral follicle populations; however, their results indicated that plasma $\mathrm{AMH}$ concentrations were useful markers for the prediction of super ovulation responses in Japanese black cows, but repeated super ovulation sessions reduce the accuracy of predictions, due to the decrease in ovarian response and $\mathrm{AMH}$ levels over time. In the case of Brahman females, the decrease in AMH levels in relation to age represents a limitation for the use of adult cows in super ovulation processes.

Gobikrushanth M, et al. [26] observed a high correlation between AMH concentrations and antral follicle count in heifers, which was not significant in cows. Moreover, Cardoso CJT, et al. [27] found that Girolando cows $(3 / 4$ Holstein $\times 1 / 4$ Gir) 24 to 60 months of age have more follicles than heifers (12 to 14 months of age), our results show an opposite tendency. In Cardoso's work plasma AMH concentrations did not differ among the ages obtaining a high correlation between the number of follicles and the plasma AMH concentrations, which contrasts with the decrease in the number of follicles and AMH levels according to the age of the Bramhan females [28].

Batista EO, et al. [29] reported that Bos indicus heifers had higher circulating AMH than Bos taurus heifers (930 vs $300 \mathrm{\rho g} / \mathrm{ml}$ ), our results with Brahman cattle show a mean level of $297.25 \mathrm{\rho g} / \mathrm{ml}$ for the whole group being the maximum level for 12 month old heifers of about $320 \mathrm{pg} / \mathrm{ml}$ whoch is more similar to the level reported for Bos Taurus heifers of the study by Batista EO, et al. [29].

In our data, the regression analysis showed a direct and significant association between ovary size and follicle count, which is consistent with various studies in cattle that report that large ovaries are associated with higher antral follicle count (Cushman RA, et al. [5]; Ireland JJ, et al. [2]; Modina SC et al. [6]).

Cows with similar ages and smaller ovaries have lower follicular counts. This affects their reproductive parameters, such as the conception rate and the interval between births, since they are also associated, as reported by the literature. These factors imply a greater economic loss in the herds. Given these events, the determination of the AMH level could be considered as an indicator of the ovarian reserve for the future selection of female embryo donors.

After all the previous comments, our conclusion is: an inverse relationship between age and follicle population is evidenced, since the results reveal an inverse linear adjustment between small follicle and total follicles with cow age, with higher values between 18 and 24 months.

Similarly, antimüllerian hormone levels decrease with the age of animals with the highest levels in the ages between 18 and 24 months. So in advanced ages the level of AMH can be considered for the discarding of donor cows [30]. 
A direct linear relationship was observed between the size of the ovary and the average count of small, large and total follicles.

\section{Acknowledgements}

To the Polytechnic Agricultural College of Manabí for its valuable contribution that made this research possible.

\section{Conflict of Interest}

The authors declare no conflicts of interest.

\section{References}

1. Erickson BH, Reynolds RA, Murphree RL (1976) Ovarian characteristics and reproductive performance of the aged cow. Biol Reprod 15: 555-560.

2. Ireland JJ, Smith GW, Scheetz D, Jimenez-Krassel F, Folger JK, et al. (2011) Does size matter in females? An overview of the impact of the high variation in the ovarian reserve on ovarian function and fertility, utility of anti-Müllerian hormone as a diagnostic marker for fertility and causes of variation in the ovarian reserve in cattle. Reprod Fertil Dev 23: 1-14.

3. Findlay JK, Hutt KJ, Hickey M, Anderson RA (2015) How is the number of primordial follicles in the ovarian reserve established? Biol Reprod 93: 111.

4. Singh J, Domínguez M, Jaiswal R, Adams GP (2004) A simple ultrasound test to predict the superstimulatory response in cattle. Theriogenology 62: 227-243.

5. Cushman RA, Allan MF, Kuehn LA, Snelling WM, Cupp AS, et al. (2009) Evaluation of antral follicle count and ovarian morphology in crossbred beef cows: investigation of influence of stage of the estrous cycle, age, and birth weight. J Anim Sci 87: 1971-1980.

6. Modina SC, Tessaro I, Lodde V, Franciosi F, Corbani D, et al. (2014) Reductions in the number of mid-sized antral follicle are associated with markers of premature ovarian senescence in dairy cows. Reprod Fertil Dev 26: 235-244.

7. Jimenez-Krassel F, Folger JK, Ireland JL, Smith GW, Hou X, et al. (2009) Evidence that high variation in ovarian reserves of healthy young adults has a negative impact on the corpus luteum and endometrium during estrous cycles in cattle. Biol Reprod 80: 12721281.

8. Martinez MF, Sanderson N, Quirke LD, Lawrence SB, Juengel JL (2016) Association between antral follicle count and reproductive measures in New Zealand lactating dairy cows maintained in a pasture-based production system. Theriogenology 85: 466-475.

9. Silva-Santos KC, Santos GM, Koetz Júnior C, Morotti F, Siloto LS, et al. (2014) Antral follicle populations and embryo production--in vitro and in vivo--of Bos indicus-taurus donors from weaning to yearling ages. Reprod Domest Anim 49: 228-232.

10. Koyama K, Koyama T, Sugimoto M (2018) Repeatability of antral follicle count according parity in dairy cows. J Reprod Dev 64: 535539.

11. Souza AH, Carvalho PD, Rozner AE, Vieira LM, Hackbart KS, et al. (2015) Relationship between circulating anti-Mullerian hormone (AMH) and superovulatory response of high-producing dairy cows. J Dairy Sci 98: 169-178.

12. Baruselli PS, Batista EOS, Ferreira RM (2016) Plasma anti-Müllerian hormone allows reproductive selection of donors with greater potential of embryo production. Spermova 6: 1-13.
13. Monniaux D, Clément F, Dalbiès-Tran R, Estienne A, Fabre $S$, et al. (2014) The ovarian reserve of primordial follicles and the dynamic reserve of antral growing follicles: what is the link? Biol Reprod 90: 85.

14. Gobikrushanth M, Purfield DC, Colazo MG, Butler ST, Wang Z, et al. (2018) The relationship between serum anti-Müllerian hormone concentrations and fertility, and genome-wide associations for antiMüllerian hormone in Holstein cows. J Dairy Sci 101: 7563-7574.

15. Zangirolamo AF, Morotti F, da Silva NC, Sanches TK, Seneda MM (2018) Ovarian antral follicle populations and embryo production in cattle. Anim Reprod 15: 310-315.

16. Danielle M (2012) Superovulatory responses and embryo production in ruminants: Lessons from ovary. $28^{\text {th }}$ Annual Meeting AETE Saint Malo, France, $7^{\text {th }}-8^{\text {th }}$ September 7-40.

17. Morotti F, Barreiros TRR, Machado FZ, Gonzalez SM, Marinho LSR, et al. (2015) Is the number of antral follicles an interesting selection criterion for fertility in cattle? Anim Reprod 12: 479-486.

18. Maculan R, Pinto TLC, Moreira GM, Vasconcelos GL, Sanches JA, et al. (2018) Anti-Müllerian Hormone (AMH), antral follicle count (AFC), external morphometrics and fertility in Tabapuã cows. Anim Reprod Sci 189: 84-92.

19. Ireland JLH, Scheetz D, Jimenez-Krassel F, Themmen AP, Ward $\mathrm{F}$, et al. (2008) Antral follicle count reliably predicts number of morphologically healthy oocytes and follicles in ovaries of young adult cattle. Biol Reprod 79: 1219-1225.

20. Eborn DR, Cushman RA, Echternkamp SE (2013) Effect of postweaning diet on ovarian development and fertility in replacement beef heifers. J Anim Sci 91: 4168-4179.

21. Monniaux D, Clemente ND, Touzé JL, Belville C, Rico C, et al. (2008) Intrafollicular steroids and anti-müllerian hormone during normal and cystic ovarian follicular development in the cow. Biol Reprod 79: 387-396.

22. Rico $C$, Fabre $S$, Médigue $C$, di Clemente $N$, Clément $F$, et al. (2009) Anti-müllerian hormone is an endocrine marker of ovarian gonadotropin-responsive follicles and can help to predict superovulatory responses in the cow. Biol Reprod 80: 50-59.

23. Ireland JJ, Ward F, Jimenez-Krassel F, Ireland JL, Smith GW, et al. (2007) Follicle numbers are highly repeatable within individual animals but are inversely correlated with FSH concentrations and the proportion of good-quality embryos after ovarian stimulation in cattle. Hum Reprod 22: 1687-1695.

24. Burns DS, Jimenez-Krassel F, Ireland JL, Knight PG, Ireland JJ (2005) Numbers of antral follicles during follicular waves in cattle: evidence for high variation among animals, very high repeatability in individuals, and an inverse association with serum folliclestimulating hormone concentrations. Biol Reprod 73: 54-62.

25. Hirayama H, Naito A, Fukuda S, Fujii T, Asada M, et al. (2017) Longterm changes in plasma anti-Müllerian hormone concentration and the relationship with superovulatory response in Japanese Black cattle. J Reprod Dev 63: 95-100.

26. Gobikrushanth M, Dutra PA, Bruinje TC, Colazo MG, Butler ST, et al. (2017) Repeatability of antral follicle counts and anti-Mullerian hormone and their associations determined at an unknown stage of follicular growth and an expected day of follicular wave emergence in dairy cows. Theriogenology 92: 90-94.

27. Cardoso CJT, de Oliveira Junior JS, Kischel H, da Silva WAL, da Silva Arruda ED, et al. (2018) Anti-Müllerian hormone (AMH) as a predictor of antral follicle population in heifers. Anim Reprod 15: 12-16. 
28. Morotti F, Santos GMG, Júnior CK, Silva-Santos KC, Roso VM, et al. (2017) Correlation between phenotype, genotype and antral follicle population in beef heifers. Theriogenology 91: 21-26.

29. Batista EO, Macedo GG, Sala RV, Ortolan MD, Sá Filho MF, et al. (2014) Plasma antimullerian hormone as a predictor of ovarian antral follicular population in Bos indicus (Nelore) and Bos taurus (Holstein) heifers. Reprod Domest Anim 49: 448-452.

30. Jimenez-Krassel F, Scheetz DM, Neuder LM, Ireland JL, Pursley JR, et al. (2015) Concentration of anti-Müllerian hormone in dairy heifers is positively associated with productive herd life. J Dairy Sci 98 : 3036-3045. 